\title{
Occurrence of Naturally Acetylated Lignin Units
}

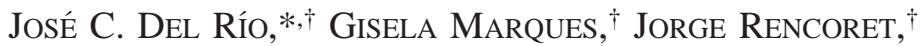 \\ Ángel T. MartíneZ, ${ }^{\ddagger}$ AND ANA GutiÉRreZ ${ }^{\dagger}$ \\ Instituto de Recursos Naturales y Agrobiología de Sevilla, CSIC, P.O. Box 1052, 41080 Seville, \\ Spain, and Centro de Investigaciones Biológicas, CSIC, Ramiro de Maeztu 9, E-28040 Madrid, Spain
}

\begin{abstract}
This work examines the occurrence of native acetylated lignin in a large set of vascular plants, including both angiosperms and gymnosperms, by a modification of the so-called Derivatization Followed by Reductive Cleavage (DFRC) method. Acetylated lignin units were found in the milled wood lignins of all angiosperms selected for this study, including mono- and eudicotyledons, but were absent in the gymnosperms analyzed. In some plants (e.g., abaca, sisal, kenaf, or hornbeam), lignin acetylation occurred at a very high extent, exceeding $45 \%$ of the uncondensed (alkyl-aryl ether linked) syringyl lignin units. Acetylation was observed exclusively at the $\gamma$-carbon of the lignin side chain and predominantly on syringyl units, although a predominance of acetylated guaiacyl over syringyl units was observed in some plants. In all cases, acetylation appears to occur at the monomer stage, and sinapyl and coniferyl acetates seem to behave as real lignin monomers participating in lignification.
\end{abstract}

KEYWORDS: Lignin; angiosperms; gymnosperms; eudicotyledons; monocotyledons; coniferyl acetate; sinapyl acetate; abaca; sisal; kenaf; hornbeam; Derivatization Followed by Reductive Cleavage (DFRC)

\section{INTRODUCTION}

Lignin is a principal structural component of cell walls in higher terrestrial plants. In addition to structural support and pathogen defense, lignin functions in water transport as a hydrophobic constituent of vascular phloem and xylem cells. Lignins are complex polymers formed by the dehydrogenative polymerization of three main monolignols, $p$-coumaryl, coniferyl, and sinapyl alcohols. Gymnosperm lignins are mainly formed from coniferyl alcohol, together with small proportions of $p$-coumaryl alcohol. Angiosperm lignins are mainly formed from coniferyl and sinapyl alcohols with small amounts of $p$-coumaryl alcohol. A considerable variation in the contribution of these three alcohol precursors is observed in lignins from herbaceous plants $(1-4)$. After their synthesis, the lignin monomers are transported to the cell wall, where they are polymerized in a combinatorial fashion by free radical coupling mechanisms in a reaction mediated by peroxidases, generating a variety of structures within the lignin polymer (5-7).

Some lignins are known to be naturally acetylated at the $\gamma$-carbon of the side chain. Acetates have been reported to occur in the lignin of a limited number of hardwoods and nonwoody plants $(1,8,9)$. In particular, kenaf bast lignin has been found to be extensively $\gamma$-acetylated and predominantly on syringyl units, although the role of such a highly acetylated lignin is not yet known. Recent studies have provided strong evidence that sinapyl acetate is implicated as a monomer in lignification in

* Author to whom correspondence should be addressed (telephone +34 954624711; fax +34 954624002; e-mail delrio@irnase.csic.es).

Instituto de Recursos Naturales y Agrobiología de Sevilla, CSIC

$\doteqdot$ Centro de Investigaciones Biológicas, CSIC. kenaf bast fibers and that the naturally acetylated polymeric lignin derives not from acetylation of the lignin polymer but from polymerization of pre-acetylated monolignols $(9,10)$. Other acids are also known to occur naturally acylating lignin; thus, grass lignins are partially $p$-coumaroylated and some hardwood lignins such as poplar, aspen, or willow are $p$-hydroxybenzoylated $(7,11-18)$.

Naturally acetylated lignins may also occur in other plants, but their occurrence has probably being missed due to the limitations of the analytical procedures used for their isolation and/or structural characterization. Natural acetates present on lignin might have been hydrolyzed and removed when traditional isolation methods (such as alkaline extraction often applied to nonwood lignins) and degradative procedures for chemical characterization (such as nitrobenzene oxidation, $\mathrm{CuO}$ oxidation, or thioacidolysis) were used. Indeed, for spectroscopic analysis, for example, using nuclear magnetic resonance (NMR), lignin is frequently acetylated for improved solubility and spectroscopic properties and, therefore, native acetates cannot be seen. Recently, we reported the occurrence of acetylated lignins in some herbaceous plants, including kenaf, jute, sisal, and abaca, characterized by a high syringyl (S) to guaiacyl $(G)$ ratio, by the use of pyrolysis coupled to gas chromatographymass spectrometry (Py-GC/MS) (19-21), although the method used hindered the determination of the extent of acetylation. In this work we have studied the occurrence and abundance of native acetylated lignin units in the milled wood lignins (MWL) isolated from a wide set of vascular plants, including gymnosperms and angiosperms (mono- and eudicotyledons). For this purpose, we have used a modification of the so-called Derivatization Followed by Reductive Cleavage (DFRC) degradation 
Table 1. Abundance (Molar Yields) of the DFRC' Degradation Monomers of the MWL Isolated from the Different Plants Selected for This Study, S/G Ratios, and Relative Abundances of Acetylated Lignin Moieties

\begin{tabular}{|c|c|c|c|c|c|c|c|c|c|c|}
\hline \multirow[b]{2}{*}{ order } & \multirow[b]{2}{*}{ family } & \multirow[b]{2}{*}{ species } & \multirow[b]{2}{*}{ name } & \multicolumn{7}{|c|}{ monomers ( $\mu \mathrm{mol} / \mathrm{g}$ of lignin) } \\
\hline & & & & $G$ & $\mathrm{G}_{\mathrm{ac}}$ & $S$ & $\mathrm{~S}_{\mathrm{ac}}$ & $S / G$ & $\% \mathrm{~S}_{\mathrm{ac}}{ }^{a}$ & $\% \mathrm{G}_{\mathrm{ac}}{ }^{\mathrm{b}}$ \\
\hline \multicolumn{11}{|l|}{$\begin{array}{l}\text { angiosperms } \\
\text { monocotyledons }\end{array}$} \\
\hline Asparagales & Agavaceae & Agave sisalana & sisal & 122 & 124 & 108 & 378 & 2.0 & 77.7 & 50.4 \\
\hline Arecales & Arecaceae & Cocos nucifera & palm tree & 819 & 5 & 174 & 14 & 0.2 & 7.4 & 0.6 \\
\hline Poales & Poaceae & Bambusa sp. & bamboo & 256 & 13 & 280 & 4 & $1.1^{c}$ & $1.2^{c}$ & 4.8 \\
\hline $\begin{array}{l}\text { Zingiberales } \\
\text { eudicotyledons }\end{array}$ & Musaceae & Musa textilis & abaca & 50 & 3 & 21 & 131 & $3.0^{c}$ & $80.3^{c}$ & 5.6 \\
\hline Fagales & Fagaceae & Fagus sylvatica & beech & 126 & 2 & 165 & 20 & 1.4 & 10.8 & 1.6 \\
\hline Fagales & Betulaceae & Carpinus betulus & hornbeam & 146 & 4 & 230 & 185 & 2.8 & 44.6 & 2.7 \\
\hline Rosales & Cannabaceae & Cannabis sativa & hemp & 286 & 2 & 177 & 2 & 0.6 & 1.1 & 0.7 \\
\hline Malvales & Malvaceae & Hibiscus cannabinus & kenaf & 390 & 38 & 543 & 780 & 3.1 & 59.0 & 8.9 \\
\hline Malvales & Malvaceae & Corchorus capsularis & jute & 299 & 1 & 336 & 23 & 1.2 & 6.4 & 0.3 \\
\hline Malpighiales & Salicaceae & Populus tremula & aspen & 651 & 5 & 662 & 8 & 1.0 & 1.2 & 0.8 \\
\hline $\begin{array}{l}\text { Myrtales } \\
\text { gymnosperms }\end{array}$ & Myrtaceae & Eucalyptus globulus & eucalypt & 154 & 8 & 275 & 3 & 2.3 & 1.1 & 4.9 \\
\hline Coniferales & Pinaceae & Picea abies & spruce & 520 & 0 & 0 & 0 & 0.0 & & 0.0 \\
\hline Coniferales & Pinaceae & Pinus sylvestris & pine & 402 & 0 & 0 & 0 & 0.0 & & 0.0 \\
\hline
\end{tabular}

${ }^{a} \% \mathrm{~S}_{\mathrm{ac}}$ is the percentage of acetylated $\mathrm{S}$ units with respect to the total $\mathrm{S}$ units. ${ }^{b} \% \mathrm{G}_{\mathrm{ac}}$ is the percentage of acetylated $\mathrm{G}$ units with respect to the total $\mathrm{G}$ units. ${ }^{c}$ Some amounts of $\gamma$-p-coumaroylated $S$ units were found (27 and $11 \mu \mathrm{mol} / \mathrm{g}$ of lignin for bamboo and abaca, respectively) and were included in the estimation of total $\mathrm{S}$ units for the calculation of $S / G$ and $\% S_{a c}$.

method (22-24). DFRC is a simple and powerful method that selectively and efficiently cleaves $\alpha$-ether and $\beta$-ether linkages and allows quantitative analysis of structural units in etherified lignin and also provides some information on carbon-carbonlinked lignin by analysis of the dimeric structures released. DFRC includes two key steps: (i) solubilization of lignin by bromination and acetylation with acetyl bromide and (ii) reductive cleavage of the aryl ether bonds in lignin with zinc dust. Identification of the resulting monomeric and dimeric degradation products by GC-MS gives valuable information on the lignin structure. However, and most importantly, DFRC leaves $\gamma$-esters intact, allowing the analysis of native $\gamma$-acylated lignin. Thus, the method allowed to confirm that $p$-coumarate groups are attached at the $\gamma$-carbon of grass lignins, predominantly on syringyl units (17). However, the DFRC method uses acetylating reagents that interfere in the analysis of native acetates in lignin, but with appropriate modification by substituting acetylation by propionylation (25), it is possible to obtain significant information and clues about the occurrence and extent of native lignin acetylation. In this paper, we use this method to investigate the presence of naturally acetylated lignin units in a set of vascular plants, including angiosperms and gymnosperms.

\section{MATERIALS AND METHODS}

Samples. The plant samples selected for this study are listed in Table 1. They consist of both woody and nonwoody angiosperms (monoand eudicotyledons) and gymnosperms. Among the woody angiosperms, wood of beech (Fagus sylvatica), European hornbeam (Carpinus betulus), aspen (Populus tremula), and eucalyptus (Eucalyptus globulus) were selected. The nonwoody angiosperm samples consisted of bast fibers obtained from the stalk phloem layer of bamboo (Bambusa sp.), hemp (Cannabis sativa), kenaf (Hibiscus cannabinus), and jute (Corchorus capsularis); leaf fibers of sisal (Agave sisalana) and abaca (Musa textilis); and coir, a coarse fiber obtained from the outer shell of coconut from the palm tree (Cocos nucifera). Among gymnosperm woods, Scots pine (Pinus sylvestris) and Norway spruce (Picea abies) were selected for this study. Wood and nonwoody plants were finely ground to sawdust using a knife mill (Analysenmühle A10, Janke and Kunkel GmbH, Staufen, Germany) before analysis. MWL was extracted from finely ball-milled $(150 \mathrm{~h})$ plant material, free of extractives and hot water soluble material, using dioxane/water $(9: 1, \mathrm{v} / \mathrm{v})$, followed by evaporation of the solvent, and purified as described (26). The final yields ranged from 5 to $15 \%$ of the original lignin content. Extension of milling time, which would increase yield, was avoided to prevent chemical modifications on the lignin structure.

DFRC. A modification of the standard DFRC method by using propionyl instead of acetyl reagents (DFRC') was used (25). Lignins $\left(10 \mathrm{mg}\right.$ ) were stirred for $2 \mathrm{~h}$ at $50{ }^{\circ} \mathrm{C}$ with propionyl bromide in propionic acid $(8: 92, \mathrm{v} / \mathrm{v})$. The solvents and excess of bromide were removed by rotary evaporation. The products were then dissolved in dioxane/propionic acid/water (5:4:1, v/v/v), and $50 \mathrm{mg}$ of powered $\mathrm{Zn}$ was added. After $40 \mathrm{~min}$ of stirring at room temperature, the mixture was transferred into a separatory funnel with dichloromethane and saturated ammonium chloride. The aqueous phase was adjusted to $\mathrm{pH}$ $<3$ by adding $3 \% \mathrm{HCl}$, the mixture vigorously mixed, and the organic layer separated. The water phase was extracted twice more with dichloromethane. The combined dichloromethane fractions were dried over anhydrous $\mathrm{NaSO}_{4}$ and the filtrate was evaporated in a rotary evaporator. The residue was subsequently propionylated for $1 \mathrm{~h}$ in 1.1 $\mathrm{mL}$ of dichloromethane containing $0.2 \mathrm{~mL}$ of propionic anhydride and $0.2 \mathrm{~mL}$ of pyridine. The propionylated lignin degradation compounds were collected after rotary evaporation of the solvents and subsequently analyzed by GC-MS.

GC-MS Analysis. The GC-MS analyses were performed with a Star 3400 GC (Varian) equipped with a Saturn 2000 ion trap detector (Varian) using a $12 \mathrm{~m} \times 0.25 \mathrm{~mm}$ i.d., $0.1 \mu \mathrm{m}$, DB-5HT capillary column (J\&W Scientific, Folsom, CA). The oven was heated from 50 (held for $0.2 \mathrm{~min}$ ) to $100{ }^{\circ} \mathrm{C}$ at $30{ }^{\circ} \mathrm{C} / \mathrm{min}$, then raised to $300{ }^{\circ} \mathrm{C}$ at 5 ${ }^{\circ} \mathrm{C} / \mathrm{min}$, and held for $5 \mathrm{~min}$ at the final temperature. The injector and transfer line were kept at $300{ }^{\circ} \mathrm{C}$. Helium was used as the carrier gas at a rate of $2 \mathrm{~mL} / \mathrm{min}$.

Quantification of the released individual monomers was performed using tetracosane as external standard and by assuming response factors similar to those of the acetylated monomers reported in Lu and Ralph (22), although without authentication on our instrument. Molar yields were calculated on the basis of molecular weights of the respective propionylated (or acetylated) compounds.

\section{RESULTS AND DISCUSSION}

The MWL isolated from the different vascular plants selected for this study, including angiosperms and gymnosperms, were analyzed according to the modified DFRC' method developed by Lu and Ralph (25) to investigate the occurrence of naturally acetylated lignin moieties. However, we have to emphasize here 

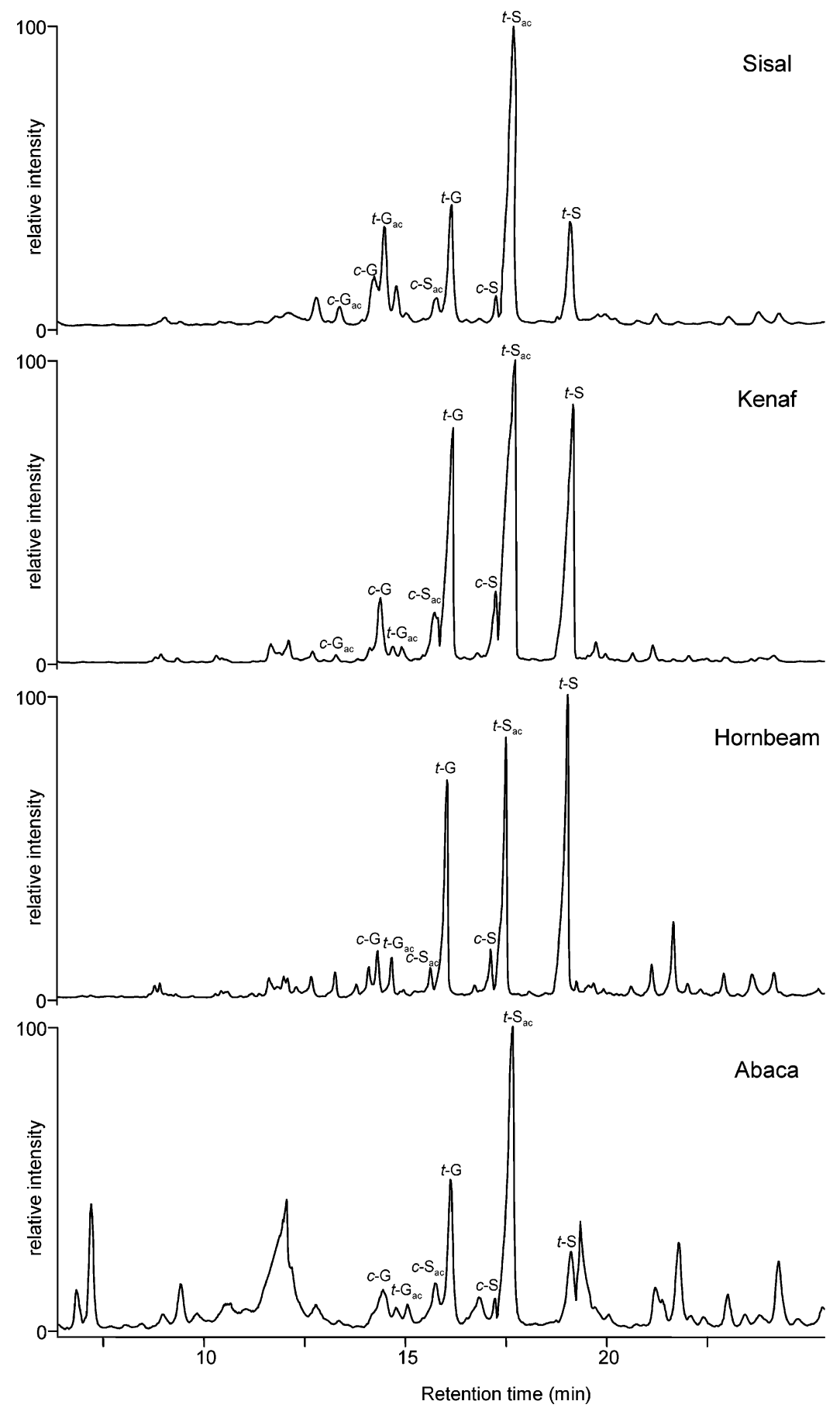

Figure 1. Chromatograms of the DFRC' degradation products of selected MWL from sisal, kenaf, hornbeam, and abaca. $c-G, t-G, c-S$, and $t-S$ are the cis-and trans-guaiacyl and syringyl monomers, respectively. $c-G_{\mathrm{ac}}, t-\mathrm{G}_{\mathrm{ac}}, c-\mathrm{S}_{\mathrm{ac}}$, and $t-\mathrm{S}_{\mathrm{ac}}$ are the originally acetylated cis- and trans-guaiacyl and syringyl monomers, respectively.

that the monomeric degradation products released by DFRC' originate from etherified lignin units because this method cleaves only $\alpha$ - and $\beta$-aryl ether bonds. The abundance of guaiacyl lignin units, which form $5-5^{\prime}$ linkages, may also be underestimated.

The chromatograms of the DFRC' degradation products of selected MWL samples are shown in Figure 1. All of the analyzed lignins released the cis and trans isomers of guaiacyl $(c-\mathrm{G}$ and $t-\mathrm{G})$ and syringyl ( $c$-S and $t-\mathrm{S}$ ) lignin monomers (as their propionylated derivatives) in different proportions, arising from normal $(\gamma-\mathrm{OH})$ units in lignin. In addition, the presence of originally $\gamma$-acetylated guaiacyl $\left(c-\mathrm{G}_{\mathrm{ac}}\right.$ and $\left.t-\mathrm{G}_{\mathrm{ac}}\right)$ and syringyl $\left(c-\mathrm{S}_{\mathrm{ac}}\right.$ and $\left.t-\mathrm{S}_{\mathrm{ac}}\right)$ lignin units could also be clearly observed in the chromatograms of most of the analyzed lignins. The structures and mass fragments of these compounds arising from $\gamma$-OH and from $\gamma$-acetylated lignin units are depicted in Figure 2. Acetylation occurred exclusively at the $\gamma$-carbon of the lignin side chain, as already reported for kenaf $\operatorname{lignin}(1,25)$. In all samples, coniferyl and sinapyl acetates presented a predominance of the trans-over the cis-form, as also occurred with the corresponding nonacetylated alcohols.

The results from the DFRC' analysis of the MWL selected for this study, namely, the molar yields of the released monomers, the $\mathrm{S} / \mathrm{G}$ ratios, and the percentages of naturally acetylated guaiacyl $\left(\% \mathrm{G}_{\mathrm{ac}}\right)$ and syringyl $\left(\% \mathrm{~S}_{\mathrm{ac}}\right)$ lignin moieties, are presented in Table 1. The yields of the released monomers were in the same range as previously observed in the DFRC 
<smiles>CCCOCC=Cc1ccc(OCC)c(OC)c1</smiles>

G

$M^{+}=292 ;\left[M^{+}-56\right]=236$<smiles>CCCOc1ccc(/C=C/COC(C)=O)cc1OC</smiles>

$\mathbf{G}_{\mathrm{ac}}$

$\mathrm{M}^{+}=278 ;\left[\mathrm{M}^{+}-56\right]=222$<smiles>COc1cc(/C=C/COC(C)C)cc(OC)c1OC</smiles>

$\mathrm{S}$

$\mathrm{M}^{+}=322 ;\left[\mathrm{M}^{+}-56\right]=266$

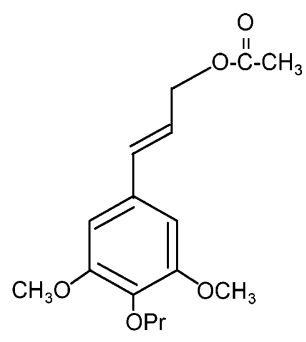

$\mathrm{S}_{\mathrm{ac}}$

$\mathrm{M}^{+}=308 ;\left[\mathrm{M}^{+}-56\right]=252$
Figure 2. Structures and mass fragments of the $\gamma-\mathrm{OH}(\mathrm{G}$ and $\mathrm{S})$ and naturally $\gamma$-acetylated $\left(\mathrm{G}_{\mathrm{ac}}\right.$ and $\left.\mathrm{S}_{\mathrm{ac}}\right)$ lignin monomers released after DFRC' of MWL.

degradation of other isolated lignins $(17,24)$. As shown in Table 1, naturally acetylated lignin units were found to occur in all angiosperms analyzed in the present study, including both monoand eudicotyledons. However, no traces of acetylated lignin units could be found in the MWL of the two gymnosperms (pine and spruce) studied here. The data also indicated that in most lignin samples acetylation occurred predominantly on syringyl units, whereas only traces of acetylated guaiacyl units were detected, although in bamboo and eucalyptus lignins, with a low extent of acetylation, this occurred preferentially on guaiacyl units. We can exclude acetylation as an artifact produced during the lignin isolation protocol because MWL from pine and spruce (where no traces of acetylated units could be detected) were also isolated using the same procedure as the rest of the samples. Indeed, acetates were found predominantly on S lignin units and exclusively at the $\gamma$-carbon, which suggests that they are naturally present. Finally, direct DFRC' of some whole fibers (such as sisal and kenaf), without previous lignin isolation, gave also similar results.

The occurrence of naturally acetylated lignin units seems to be widespread among angiosperms and restricted only to this group of vascular plants, being particularly abundant in syringylrich lignins. Especially important is the high extent of lignin acetylation observed in the MWL from the herbaceous plants abaca, sisal, and kenaf and in the hardwoods hornbeam and, to a minor extent, beech, all of them characterized by high S/G ratios. However, we also noted the acetylation of $S$ units in coir lignin, which is characterized by a very low $\mathrm{S} / \mathrm{G}$ ratio $(0.2)$. The high extent of acetylation of kenaf lignin has been previously reported by NMR and DFRC' $(1,25)$. The occurrence<smiles>COc1cc(C=CCOC(C)=O)cc(C=CCOC(C)=O)c1</smiles><smiles>COc1cc(C2OC(COC(C)=O)C(COC(C)=O)C2COC(C)=O)cc(OC)c1O</smiles><smiles>COc1cc(C=CCO)cc(C=CCOC(C)=O)c1OC</smiles><smiles>COc1cc(C(O)C2CO[C@H](c3cc(OC)c(O)c(OC)c3)[C@H]2COC(C)=O)cc(OC)c1O</smiles><smiles>COc1cc(C=CCO)cc(OC)c1O</smiles><smiles>COc1cc(C2OCC3C(c4cc(OC)c(O)c(OC)c4)OCC23)cc(OC)c1O</smiles>

Figure 3. Structures of the tetrahydrofuran dimers arising from the $\beta-\beta^{\prime}$ coupling of sinapyl alcohol and sinapyl acetate: I, $\beta-\beta^{\prime}$ coupling product of two sinapyl acetates; II, $\beta-\beta^{\prime}$ coupling product of a sinapyl alcohol and a sinapyl acetate; III, $\beta-\beta^{\prime}$ coupling product (syringaresinol) of two sinapyl alcohols. 
<smiles>CCOc1c(OC)cc2c(c1OC)C(c1cc(OC)c(OC(C)=O)c(OC(C)(C)C)c1)C(COC(C)=O)C(COC)C2</smiles><smiles>CCCCOc1c(OC)cc2c(c1O)C(c1cc(OC)c(OCC)c(OC)c1)C(COC(=O)O)C(COCCC)C2</smiles>

II'a; $M^{+}=630 ;[M-56]^{+}=574$

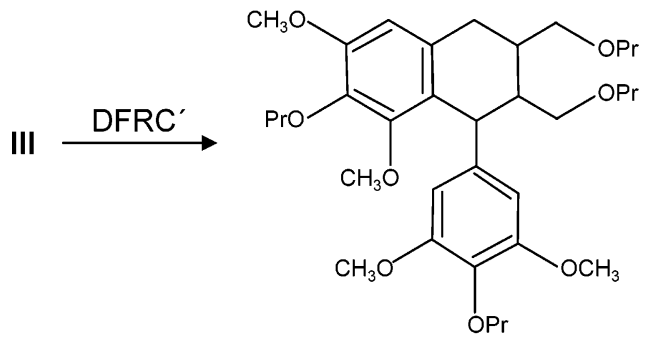<smiles>CCOc1c(OC)cc(C2c3c(cc(OC)c(OC)c3OC)CC(COC)C2COC(C)=O)cc1OC</smiles>

II'b; $M^{+}=630:[M-56]^{+}=574$

III'; $\mathrm{M}^{+}=644 ;[\mathrm{M}-56]^{+}=588$

Figure 4. Aryltetralin products resulting from the DFRC' degradation of the di- (I'), mono- (II'a and II'b), and unacetylated (III') $\beta-\beta^{\prime}$ coupling structures. The molecular mass and base peaks are indicated under the structures.

of naturally acetylated lignin units was also reported in kenaf, jute, sisal, and abaca by Py-GC/MS of the whole fibers, although the extent of acetylation could not be determined due to the limitations of the technique (19-21). Interestingly, the high extent of acetylation of sisal MWL included both S units (78\%) and $\mathrm{G}$ units $(50 \%)$, whereas in the case of abaca, kenaf, or hornbeam lignins, acetylation occurred almost predominantly on $\mathrm{S}$ units $(80,59$, and $45 \%$, respectively) and only a minor degree of acetylation was observed on $\mathrm{G}$ units $(6,9$, and $3 \%$, respectively).

On the other hand, it has been recently and elegantly proved that acetylated lignin in kenaf derives from polymerization of pre-acetylated monolignols and not from acetylation of the lignin polymer $(9,10)$. Acetylation of lignin at monomer stage only partially affects the course of the coupling reactions, since these acetylated monolignols can still undergo the $\beta-O-4^{\prime}$-coupling reactions that incorporate them into the lignin polymer. Obviously, the resulting acetylated lignin polymer is produced and has the mechanical properties required by the plant. However, the presence of $\gamma$-acetylated monolignols alters to some extent the structure of the lignins because the $\gamma-\mathrm{OH}$ group of a monolignol participates in some postcoupling reactions, such as after $\beta-\beta^{\prime}$ coupling, internally trapping the quinone methide. With the $\gamma-\mathrm{OH}$ group acetylated, such internal reactions are no longer possible and the quinone methide must be rearomatized by trapping an external nucleophile, usually water, and forming as a result new $\beta-\beta^{\prime}$ products in the lignin different from the expected resinol structures formed from nonacetylated mono- lignols (9). Figure 3 shows the different tetrahydrofuran structures arising from the $\beta-\beta^{\prime}$ homo- and cross-coupling of the two sinapyl (acetylated and nonacetylated) monolignols. It is clear that structures I and II can be formed only if sinapyl alcohol is pre-acetylated and then undergoes $\beta-\beta^{\prime}$ coupling. These $\beta-\beta^{\prime}$ homo- (I) and cross-coupled (II) structures arising from pre-acetylated sinapyl alcohol were found in kenaf lignin by DFRC ${ }^{\prime}$ and 2D-NMR $(9,10)$, which unequivocally demonstrates that sinapyl alcohol is pre-acetylated prior to lignification and that sinapyl acetate behaves as a real monolignol in kenaf lignin.

We also investigated the presence of the tetrahydrofuran structures arising from $\beta-\beta^{\prime}$ coupling of sinapyl acetates in the MWL selected for this study, by using the DFRC' method. The DFRC' degradation products of the tetrahydrofuran structures depicted in Figure $\mathbf{3}$ are presented in Figure 4, and their mass spectra have already been published (9). Compounds I', II'a, and $\mathbf{I I}^{\prime} \mathbf{b}$, arising from originally acetylated sinapyl alcohol, together with compound III', arising from the resinol structure, were found in most of the samples analyzed. Figure 5 shows the chromatograms (sum of the single ion chromatograms of the respective base peaks) of the DFRC' degradation products of the tetrahydrofuran structures arising from $\beta-\beta^{\prime}$ coupling of sinapyl alcohol (and its acetylated counterpart) in selected samples. It is interesting to note the relatively high amounts of compounds $\mathbf{I}^{\prime}$, II'a, and $\mathbf{I I}^{\prime} \mathbf{b}$, arising from native acetylated lignin units in kenaf and especially in sisal lignin, and the complete absence of $\beta-\beta^{\prime}$ coupling structures in abaca lignin. 


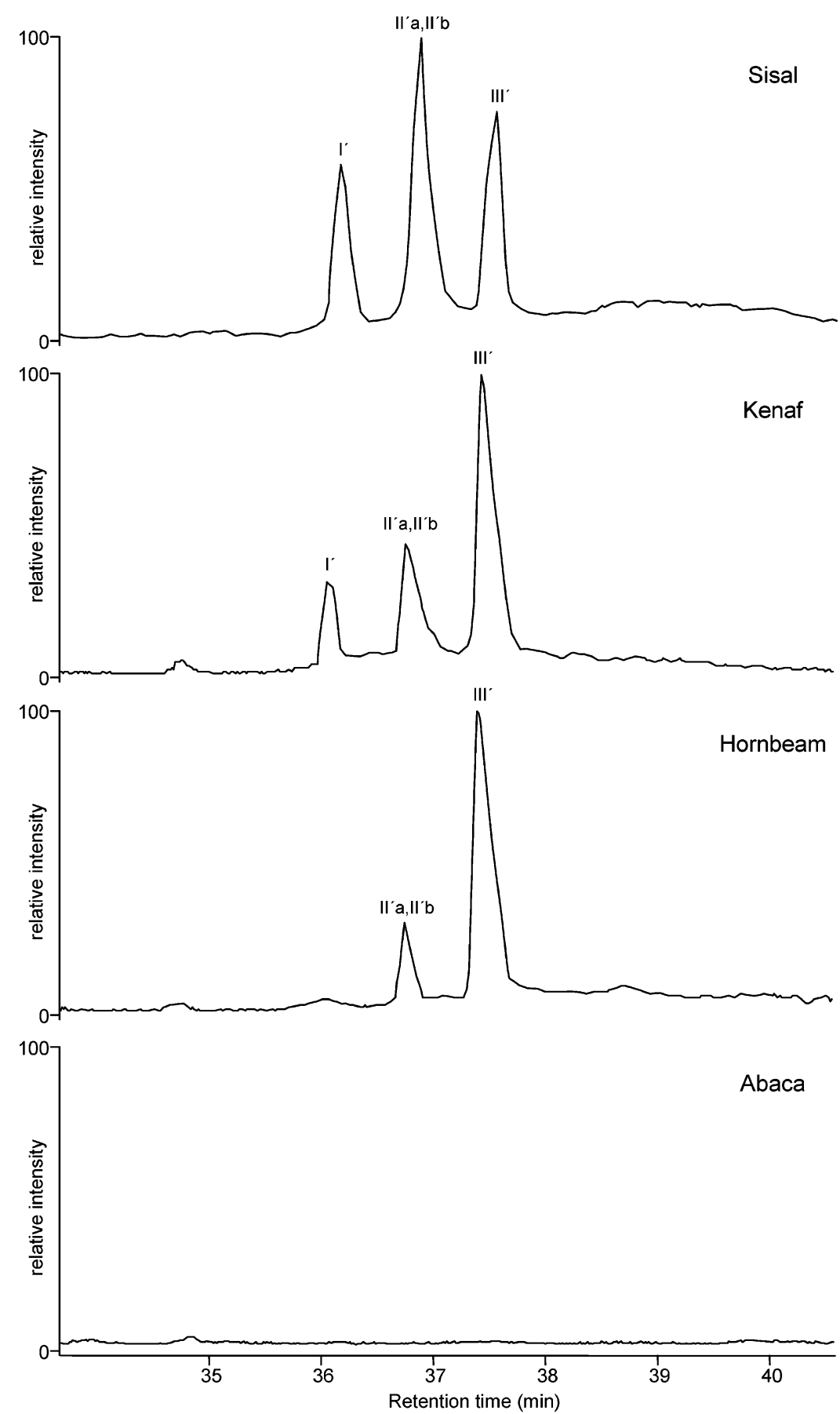

Figure 5. Detail of reconstructed (sum of the ions at $\mathrm{m} / \mathrm{z} 560,574$, and 588 ) chromatograms of the DFRC' degradation products of selected MWL from sisal, kenaf, hornbeam, and abaca, showing the presence of aryltetralin $\beta-\beta^{\prime}$ products containing two (I'), one (II'a and II'b), and no (III') native acetates.

However, we also observed that the respective tetrahydrofuran structures arising from the $\beta-\beta^{\prime}$ coupling of the acetylated guaiacyl counterparts could not be found, even in the case of sisal lignin (with $50 \%$ acetylated ether-linked $\mathrm{G}$ units). The presence of compound $\mathbf{I}^{\prime}$ (arising from structure $\mathbf{I}$ in lignin) and compounds II'a and II'b (arising from structure II) in the DFRC' degradation products of sisal, kenaf, jute, hornbeam, and other lignins clearly indicates that in these samples sinapyl alcohol is pre-acetylated and behaves as a real monolignol, participating in post-cross-coupling reactions. Therefore, it is possible that in all angiosperms, in which we have shown the occurrence of acetylated lignin units, sinapyl and possibly coniferyl acetates participate in lignification as true lignin precursors. This implies that the naturally acetylated polymeric lignins in all of these plants derive not from acetylation of the lignin polymer but from polymerization of pre-acetylated monolignols, as already suggested (9). Thus, the traditional concepts of both lignin biosynthesis and structure must be reconsidered. This indicates, in agreement with other authors $(7,27)$, that the lignification process is very flexible and that the definition of lignin must not be restricted to a polymer of the three traditional hydroxycinnamyl alcohols.

The relative abundance of the compounds released in Figure 5 gives some additional information. In sisal, the relative molar abundance of the acetylated versus the nonacetylated sinapyl alcohols forming $\beta-\beta^{\prime}$ linkages is $44: 56$, with a predominance of the nonacetylated sinapyl alcohol, whereas their relative molar abundances in ether-linked structures is $78: 22$, with a strong 
predominance of sinapyl acetate. This indicates that sinapyl acetate has a lower affinity to form $\beta-\beta^{\prime}$ linkages than the normal sinapyl alcohol, and therefore those lignins having a high extent of acetylation would produce lower amounts of $\beta-\beta^{\prime}$ linkages. This is in agreement with the high proportions of $\beta-O$ $4^{\prime}$ substructures present in sisal lignin, as indicated by 2D-NMR (data not shown). Interestingly, abaca MWL, with a very high extent of acetylation ( $80 \%$ of $\mathrm{S}$ units), lacks $\beta-\beta^{\prime}$ linkages, including those arising from normal nonacetylated lignin units (Figure 5), and produces almost exclusively $\beta-O-4^{\prime}$ substructures. Similar results were observed after normal DFRC and 2D-NMR (data not shown). Therefore, it seems that the high extent of $\gamma$-acetylation would favor the formation of a predominantly $\beta-O-4^{\prime}$ lignin structure. The difficulty in finding $\beta-\beta^{\prime}$ substructures arising from naturally acetylated guaiacyl lignin in sisal, despite the high abundance of this type of unit, would be perhaps due to the low amounts of $\beta-\beta^{\prime}$ linkages produced.

Although it is now evident that native acetylated lignin units are widespread, and probably ubiquitous, in angiosperms, the role of such lignin acetylation in the plant is not yet known. Some studies indicated that $\gamma$-acylation with $p$-coumarates may function as radical transfer carriers to help sinapyl alcohol incorporate into lignin when the wall peroxidases have a low reactivity with sinapyl alcohol directly (28). However, this is not the case for acetylated lignin monomers, and the function of such acetylated lignin remains unknown.

The high extent of lignin acetylation of sisal and other agaves (preliminary results on another species, Agave americana, by DFRC' $^{\prime}$ of the whole fiber, without previous lignin isolation, also indicate $>75 \%$ of acetylated $\mathrm{S}$ units) can provide some answers about its role in this plant. Because the resultant acetylated lignin polymer is more hydrophobic than normal lignin, the role of lignin acetylation could be associated with drought tolerance, as already advanced by Ralph (29). Sisal, as other agaves, is a drought-tolerant desert perennial plant successfully coping with high temperatures and desiccation. Agaves are characterized by tissue succulence and Crassulacean acid metabolism to minimize water loss. The presence of a highly acetylated lignin in agaves will increase hydrophobicity of the vascular tissues, thus helping to reduce water loss in the plant. However, abaca, despite being highly acetylated, does not have succulent leaves and is not drought tolerant, and therefore the highly acetylated lignin might have a different role for this plant. In this case, the role of the high extent of lignin acetylation could be more related with the lower affinity of acetylated monolignols to form $\beta-\beta^{\prime}$ linkages, producing a more noncondensed lignin enriched in $\beta-O-4^{\prime}$ linkages. Whatever the reason for the occurrence of acetylated lignin in plants, it seems that the mechanism for lignin acetylation confers on the plant a high flexibility to produce different types of lignins with different degrees of acetylation to adapt to different environmental conditions.

In conclusion, the presence of naturally acetylated lignin units, which in some plants make up to $80 \%$ of the uncondensed (alkyl-aryl ether linked) S lignin, has been largely underestimated. This has mainly been due to the analytical methodologies used for their isolation and structural characterization, which are not appropriate for the analysis of native acetylated lignin. Therefore, all subsequent lignin structural studies should take into account the occurrence of these moieties and accordingly adapt the methodological protocols used.

\section{LITERATURE CITED}

(1) Ralph, J. An unusual lignin from kenaf. J. Nat. Prod. 1996, 59, 341-342.

(2) Sun, R. C.; Fang, J. M.; Goodwin, A.; Lawther, J. M.; Bolton, A. J. Fractionation and characterization of ball-milled and enzyme lignin from abaca fibre. J. Sci. Food Agric. 1999, 79, 1091-1098.

(3) Sun, R. C.; Sun, X. F.; Wang, S. Q.; Zhu, W.; Wang, X. Y. Ester and ether linkages between hydroxycinnamic acids and lignin from wheat, rice, rye, and barley straws, maize stems, and fast-growing poplar wood. Ind. Crops Prod. 2002, 15, 179188.

(4) del Río, J. C.; Gutiérrez, A.; Rodríguez, I. M.; Ibarra, D.; Martínez, A. T. Composition of non-woody plant lignins and cinnamic acids by Py-GC/MS, Py/TMAH and FT-IR. J. Anal. Appl. Pyrol. 2007, 79, 39-46.

(5) Ros Barceló, A. Lignification in plant cell walls. Int. Rev. Cytol. 1997, 176, 87-132.

(6) Boerjan, W.; Ralph, J.; Baucher, M. Lignin biosynthesis. Annu. Rev. Plant Biol. 2003, 54, 519-546.

(7) Ralph, J.; Lundquist, K.; Brunow, G.; Lu, F.; Kim, H.; Schatz, P. F.; Marita, J. M.; Hatfield, R. D.; Ralph, S. A.; Christensen, J. H., et al. Lignins: natural polymers from oxidative coupling of 4-hydroxyphenylpropanoids. Phytochem. Rev. 2004, 3, 2960

(8) Sarkanen, K. V.; Chang, H. -M.; Allan, G. C. Species variation in lignins. III. Hardwood lignins. Tappi 1967, 50, 587-590.

(9) Lu, F.; Ralph, J. Preliminary evidence for sinapyl acetate as a lignin monomer in kenaf. Chem. Commun. 2002, 90-91.

(10) Lu, F.; Ralph, J. Novel $\beta-\beta$ structures in lignins incorporating acylated monolignols. In Proceedings of 13th International Symposium on Wood, Fiber, and Pulping Chemistry, Auckland, New Zealand, May 16-19, 2005; Vol. 3, pp 233-237.

(11) Smith, D. C. C. p-Hydroxybenzoate groups in the lignin of aspen (Populus tremula). J. Chem. Soc. 1955, 2347-2351.

(12) Nakano, J.; Ishizu, A.; Migata, N. Studies on lignin. XXXII. Ester groups of lignin. Tappi 1961, 44, 30-32.

(13) Monties, B.; Lapierre, C. Donnés récentes sur l'hétérogénéite de la lignine (Recent data on the heterogeneity of lignin). Physiol. Veg. 1981, 19, 327-348.

(14) Landucci, L. L.; Deka, G. C.; Roy, D. N. A. ${ }^{13}$ C NMR study of milled wood lignins from hybrid Salix clones. Holzforschung 1992, 46, 505-511.

(15) Ralph, J.; Hatfield, R. D.; Quideau, S.; Helm, R. F.; Grabber, J. H.; Jung, H.-J. G. Pathway of $p$-coumaric acid incorporation into maize lignin as revealed by NMR. J. Am. Chem. Soc. 1994, 116, 9448-9456.

(16) Sun, R. C.; Fang, J. M.; Tomkinson, J. Fractional isolation and structural characterization of lignins from oil palm trunk and empty fruit bunch fibres. J. Wood Chem. Technol. 1999, 19, 335-356.

(17) Lu, F.; Ralph, J. Detection and determination of $p$-coumaroylated units in lignin. J. Agric. Food Chem. 1999, 47, 1985-1992.

(18) Meyermans, H.; Morreel, K.; Lapierre, C.; Pollet, B.; De Bruyn, A.; Busson, R.; Herdewijn, P.; Devreese, B.; Van Beeumen, J.; Marita, J. M., et al. Modification in lignin and accumulation of phenolic glucosides in poplar xylem upon down-regulation of caffeoyl-coenzyme A $O$-methyltransferase, an enzyme involved in lignin biosynthesis. J. Biol. Chem. 2000, 275, 36899-36909.

(19) del Río, J. C.; Gutiérrez, A.; Martínez, A. T. Identifying acetylated lignin units in non-wood fibers using pyrolysis-gas chromatography/mass spectrometry. Rapid Commun. Mass Spectrom. 2004, 18, 1181-1185.

(20) Gutiérrez, A.; Rodríguez, I. M.; del Río, J. C. Chemical characterization of lignin and lipid fractions in kenaf bast fibers used for manufacturing high-quality papers. J. Agric. Food Chem. 2004, 52, 4764-4773.

(21) del Río, J. C.; Gutiérrez, A. Chemical composition of abaca (Musa textilis) leaf fibers used for manufacturing of high quality paper pulps. J. Agric. Food Chem. 2006, 54, 4600-4610. 
(22) Lu, F.; Ralph, J. Derivatization followed by reductive cleavage (DFRC method), a new method for lignin analysis: protocol for analysis of DFRC monomers. J. Agric. Food Chem. 1997, 45, 2590-2592.

(23) Lu, F.; Ralph, J. The DFRC method for lignin analysis. Part 1. A new method for $\beta$-aryl ether cleavage: lignin model studies. J. Agric. Food Chem. 1997, 45, 4655-4660.

(24) Lu, F.; Ralph, J. The DFRC method for lignin analysis. 2. Monomers from isolated lignin. J. Agric. Food Chem. 1998, 46, 547-552.

(25) Ralph, J.; Lu, F. The DFRC method for lignin analysis. 6. A simple modification for identifying natural acetates in lignin. $J$. Agric. Food Chem. 1998, 46, 4616-4619.

(26) Björkman, A. Studies on finely divided wood. Part I. Extraction of lignin with neutral solvents. Sven. Papperstidn. 1956, 59, 477-485.

(27) Sederoff, R. D.; MacKay, J.; Ralph, J.; Hatfield, R. Unexpected variation in lignin. Curr. Opin. Plant Biol. 1999, 2, 145.
(28) Takahama, U.; Oniki, T.; Shimokawa, H. A possible mechanism for the oxidation of sinapyl alcohol by peroxidase-dependent reactions in the apoplast: enhancement of the oxidation by hydroxycinnamic acids and components of the apoplast. Plant Cell Physiol. 1996, 37, 499-50.

(29) Ralph, J. Elucidation of new pathways in normal and perturbed lignification. Appita 2005, 3-13.

Received for review February 22, 2007. Revised manuscript received April 24, 2007. Accepted April 26, 2007. This study has been supported by the Spanish MEC (Project AGL2005-01748) and EU Contract NMP2-CT-2006-26456. J.R. thanks the Spanish CSIC for an I3P fellowship; G.M. thanks the Spanish Ministry of Education for a FPI fellowship.

JF0705264 